\title{
Photothermal therapy of melanoma tumor using multiwalled carbon nanotubes
}

\author{
This article was published in the following Dove Press journal: \\ International Journal of Nanomedicine \\ 20 June 2017 \\ Number of times this article has been viewed
}

\author{
Zahra Sobhani ${ }^{1,2}$ \\ Mohammad Ali Behnam ${ }^{3}$ \\ Farzin Emami ${ }^{3}$ \\ Amirreza Dehghanian ${ }^{4}$ \\ Iman Jamhiri ${ }^{5}$ \\ 'Quality Control Department, \\ Faculty of Pharmacy, ${ }^{2}$ Center for \\ Nanotechnology in Drug Delivery, \\ Faculty of Pharmacy, Shiraz University \\ of Medical Sciences, ${ }^{3}$ Opto-Electronic \\ Research Center, Electrical and \\ Electronics Engineering Department, \\ Shiraz University of Technology, \\ ${ }^{4}$ Pathology Department, ${ }^{5}$ Stem Cell \\ Technology Research Center, Shiraz \\ University of Medical Sciences, \\ Shiraz, Iran
}

\begin{abstract}
Photothermal therapy (PTT) is a therapeutic method in which photon energy is transformed into heat rapidly via different operations to extirpate cancer. Nanoparticles, such as carbon nanotubes (CNTs) have exceptional optical absorbance in visible and near infrared spectra. Therefore, they could be a good converter to induce hyperthermia in PTT technique. In our study, for improving the dispersibility of multiwalled CNTs in water, the CNTs were oxidized (O-CNTs) and then polyethylene glycol (PEG) was used for wrapping the surface of nanotubes. The formation of a thin layer of PEG around the nanotubes was confirmed through Fourier transform infrared, thermogravimetric analysis, and field emission scanning electron microscopy techniques. Results of thermogravimetric analysis showed that the amount of PEG component in the O-CNT-PEG was approximately $80 \%$ (w/w). Cell cytotoxicity study showed that O-CNT was less cytotoxic than pristine multiwalled nanotubes, and O-CNT-PEG had the lowest toxicity against HeLa and HepG2 cell lines. The effect of O-CNT-PEG in reduction of melanoma tumor size after PTT was evaluated. Cancerous mice were exposed to a continuous-wave near infrared laser diode $\left(\lambda=808 \mathrm{~nm}, P=2 \mathrm{~W}\right.$ and $\left.I=8 \mathrm{~W} / \mathrm{cm}^{2}\right)$ for 10 minutes once in the period of the treatment. The average size of tumor in mice receiving O-CNT-PEG decreased sharply in comparison with those that received laser therapy alone. Results of animal studies indicate that O-CNT-PEG is a powerful candidate for eradicating solid tumors in PTT technique.
\end{abstract}

Keywords: Photo thermal therapy, CNTs, hyperthermia, PEG, melanoma

\section{Introduction}

Cancer still remains one of the world's most disastrous diseases. Conventional cancer treatments like surgical intervention, radiation, and chemotherapeutic drugs also kill healthy cells and cause toxicity to the body. ${ }^{1}$ A promising area that is making revolutionary strides in methods of cancer treatment is cancer nanotechnology, which includes the integration of fields like engineering, material sciences, optics, pharmaceutics, chemistry, and physics with cancer biology. ${ }^{2}$

Hyperthermia is a simple method of cancer therapy in which irradiation of near infrared (NIR) light increases the local temperature of tumor and disturbs the cancer cells. Internalized nanoparticles (NPs) to the tumor sites could be stimulated by laser irradiation, to produce localized heat in the range of $40^{\circ} \mathrm{C}-45^{\circ} \mathrm{C}$ so as to destroy cancer cells. ${ }^{2-5}$ NPs such as single-walled carbon nanotubes, ${ }^{6}$ multiwalled carbon nanotubes (MWNTs), ${ }^{7,8}$ graphene,,${ }^{9,10}$ iron oxide NPs, ${ }^{11}$ gold nanorods, ${ }^{12}$ and gold nanoshells ${ }^{13,14}$ are used to transform NIR radiation to vibrational energy. Therefore, heat generation based on laser irritation could elevate malignant tissues' temperature and destroy tumors. ${ }^{15}$ Inducing high temperature for a sufficient time causes physical damage like protein denaturation and membrane lysis and could increase oxidative

\footnotetext{
Correspondence: Mohammad Ali Behnam Opto-Electronic Research Center, Electrical and Electronics Engineering Department, Airport Boulevard, Shiraz University of Technology, Shiraz,

71557-13876, Iran

Tel +98 7I 37353500

Fax +98 71 37354514

Email m.behnam@sutech.ac.ir
} 
stress, finally causing coagulative necrosis or apoptosis. ${ }^{5,15}$ Utilizing the NIR light in the range $700-1,100 \mathrm{~nm}$ to induce hyperthermia is really efficient because biological systems mainly lack chromophores to absorb NIR light. NIR wavelength, compared to other range of wavelengths, is more transmissive through the body and is poorly attenuated by biological systems. ${ }^{16,17}$ By localization and excitation of potent NPs in the tumor region, lesions could be cured without direct access to the tumor site and selectively destroyed. ${ }^{18}$ This method promises to ablate recurrent, unconventional, and inaccessible tumors. The wide electromagnetic absorbance spectrum of carbon nanotubes (CNTs) creates exceptional properties compared to other plasmonically heated nanomaterials (like gold nanoshells and nanorods) that is dependent on the size and shape of CNTs. ${ }^{19}$ CNTs promise an extraordinary combination of attributes in improving the next generation of photothermal agents because of their strong ability to transform NIR radiation into heat. ${ }^{20}$ NIR exposure of CNTs excites electrons to the excited state and releases vibrational energy through heat, which could be used to induce cell death. ${ }^{21,22}$ Studies show that CNTs can achieve thermal destruction using tenfold-lower doses in solution and using threefold-lower laser power than that required for gold nanorods, ${ }^{23}$ and these also indicate that MWNTs are more potent than bulk single-walled nanotubes in transferring the NIR light into heat. ${ }^{2}$ Studies by Murphy et $\mathrm{al}^{24}$ reported that the inflammation and fibrosis induced by CNTs could be reduced by shortening the length of CNTs. One of the conventional methods to shorten and exfoliate the CNT bundles is oxidation. Oxidation also enhances the wettability, surface reactions, functionality, and cell penetration of CNTs ${ }^{25-27}$ To improve the poor dispersibility of CNTs into aqueous media, different hydrophilic polymers can be used. Functionalization of CNTs with polyethylene glycol (PEG) moieties (PEGylation) has been utilized to enhance the solubility, biocompatibility, and cell membrane penetration of the moieties. ${ }^{28,29}$

In this study, at first we solubilized oxidized-MWNTs with PEG to enhance their hydrophilicity and biocompatibility and then evaluated their efficacy in treatment of melanoma via hyperthermia treatment in vivo.

\section{Materials and methods Materials}

Purified MWNTs (number of walls: 3-15, outer diameter: 5-20 nm, length: $1-10 \mu \mathrm{m}$ ) were purchased from Plasmachem (Berlin, Germany). PEG1000 was purchased from Sigma-Aldrich (St Louis, MO, USA). All solvent were of analytical grade.

\section{Preparation of CNTs-PEG}

For wrapping of CNTs with PEG, the CNTs should be oxidized first. For oxidation of CNTs, $1 \mathrm{~g}$ of MWNTs was sonicated with $20 \mathrm{~mL}$ nitric acid and sulfuric acid solution $(1: 3 \mathrm{v} / \mathrm{v})$ for 30 minutes. Then, the solution was refluxed for 21 hours at $100^{\circ} \mathrm{C}$. The solution was diluted with $1 \mathrm{~L}$ of deionized water, then filtered, and finally washed till the $\mathrm{pH}$ adjusted to 6 . The filtrate was dried in an oven at a temperature of $40^{\circ} \mathrm{C}$ for 24 hours. ${ }^{30-32}$ The oxidized-CNTs (O-CNTs) were ready for following steps.

$50 \mathrm{mg}$ of O-CNTs was added to $50 \mathrm{~mL}$ of deionized water containing $500 \mathrm{mg}$ of PEG1000..$^{33}$ The mixture was sonicated for 3 minutes and stirred overnight for wrapping hydrophilic polymer around the O-CNTs. The resulting solution was centrifuged at $4,000 \mathrm{rpm}$ for 10 minutes to remove any aggregates, and the supernatant containing O-CNT-PEG was collected. Excess PEG was removed by dialysis.

\section{Characterization of O-CNT-PEG}

IR measurements were performed by (Perkin Elmer Spectrum One, Fourier transform infrared [FT-IR]; Shelton, CT, USA). Thermogravimetric analysis (TGA) was carried out (BAHR-Thermoanalyse Gmbh, TGA; Hüllhorst, Germany) under dynamic atmosphere of an inert gas $\left(\mathrm{N}_{2}\right)$ at $30 \mathrm{~mL} / \mathrm{min}$ (room temperature). Field emission scanning electron microscopic (FESEM) analyses were performed (TESCAN MIRA 3-XMU, FESEM; Brno, Czech Republic). UV-Vis absorption of O-CNT-PEG was analyzed (PG instruments Ltd., T80 UV-Vis spectrophotometer, Lutterworth, UK) to determine the best photoabsorption wavelength for excitation.

\section{Cytotoxicity assay for O-CNT-PEG}

To verify the cytotoxicity of modified CNTs, the cytotoxicity of MWNT, O-CNT, and O-CNT-PEG was assessed by the standard MTT assay. Two human cell lines, human cervical cancer cells (HeLa) and human hepatocellular carcinoma cell line (HepG2), were purchased from the National Cell Bank of Pasteur Institute (Tehran, Iran). HeLa and HepG2 were cultured in Roswell Park Memorial Institute medium (RPMI)-1640 medium supplemented with $10 \%$ fetal bovine serum and $1 \%$ penicillin-streptomycin at $37^{\circ} \mathrm{C}$ in a humidified incubator with $5 \% \mathrm{CO}_{2}$. Cells in the exponential growth phase were seeded in 96-well plates at a density of $1 \times 10^{4}$ viable cells/well. After overnight incubation, cells were exposed to different concentrations of MWNT, O-CNT, and O-CNT-PEG. After 24 hours, $20 \mu \mathrm{L}$ of MTT $(5 \mathrm{mg} / \mathrm{mL})$ and $100 \mu \mathrm{L}$ of medium were introduced. The plates were incubated for 3-4 hours. The formazan crystals in each well 
were dissolved in $100 \mu \mathrm{L}$ of dimethyl sulfoxide. After complete solubilization of the dye, plates were read at $570 \mathrm{~nm}$ against $690 \mathrm{~nm}$ on an ELISA reader. The percentage of cell viability was calculated. The cell viability was estimated as the reduction of values from a dimethyl sulfoxide control, and the values were the mean of three different experiments.

\section{Tumor induction}

The metastatic murine melanoma cell line B16/F10 (NCBI C540 was purchased from the National Cell Bank of Pasteur Institute of Iran, Tehran, Iran) was cultured in RPMI 1640 medium, under $5 \% \mathrm{CO}_{2}$ at $37^{\circ} \mathrm{C}$. Then it was supplemented with $10 \%$ fetal bovine serum, $100 \mathrm{IU} / \mathrm{mL}$ of penicillin, and $100 \mu \mathrm{g} / \mathrm{mL}$ streptomycin.

For tumor induction, female C57BL/6J mice that were inbred, weighing $20-30 \mathrm{~g}$, and aged 6-8 weeks were selected. Murine melanoma cells at a count of $10^{6}-10^{7}$ were suspended in $200 \mu \mathrm{L}$ culture medium and injected hypodermically. This examination was done in the Center of Experimental and Comparative Medicine, Shiraz University of Medical Sciences, Shiraz, Iran and was cleared by the Ethical Committee of Shiraz University of Medical Sciences generously. Mice selection, methods of care, and sacrificing were the same and adhered to the guideline of Animal Care Committee of Iran Veterinary Organization. Experiments were done under aseptic situation, and the protocol of anesthesia, postoperative care, and surgical methods were the same for all mice.

\section{In vivo photothermal therapy (PTT) of tumors}

The therapeutic effect of ablation with O-CNT-PEG and laser irradiation was evaluated by monitoring the size of tumor inoculated in mice. Two weeks after melanoma cell line injection, the tumors had grown adequately (about $1 \mathrm{~cm}^{3}$ ) to start hyperthermia therapy. The mice were randomized into 3 groups ( $\mathrm{n}=5)$ and anesthetized with a combination of ketamine $10 \%(100 \mathrm{mg} / \mathrm{kg})$ and xylazine $2 \%(10 \mathrm{mg} / \mathrm{kg})$. After sedation, the hair on tumor was shaved and the skin was cleansed. Tumor sizes were measured using a caliper and evaluated with an ultrasonography machine (Ultrasonix SonixOP; Burnaby, BC, Canada) before the treatment and 3 days after the treatment. The tumor size was estimated with the following Equation:

$$
\text { Tumor volume }=\left(\mathrm{L} / \mathrm{W}^{2}\right) / 2\left(\mathrm{~mm}^{3}\right)^{34,35}
$$

where $\mathrm{L}$ and $\mathrm{W}$ represent length and width of the tumor, respectively.
The mice received treatment as follows:

Group I (O-CNT-PEG): O-CNT-PEG $(1 \mathrm{mg} / \mathrm{mL})$ was injected into the tumor at a dose of $200 \mu \mathrm{L} / \mathrm{cm}^{3}$ (tumor volume).

Group II (Laser therapy): laser therapy was done without any pretreatment with NPs.

Group III (Control): did not receive any treatment.

The tumor area in groups I and II were irradiated using an $808 \mathrm{~nm}$ continuous-wave NIR laser diode $808-2 \mathrm{~W}$ with the intensity of $8 \mathrm{~W} / \mathrm{cm}^{2}$ and spot size of $0.25 \mathrm{~cm}^{2}$ for 10 minutes. After treatment, all mice were sacrificed, the tumor size was measured, and the mass was excised for histological studies.

\section{Statistical analysis}

Data are expressed as mean \pm SD. Significant differences of the values were statistically tested using paired-sample $t$-test in each group. Multiple comparisons at multiple time points were tested using analysis of variance with repeated measures. The statistical analyses were performed by SPSS $^{\circledR}$ statistical software, version 20.0 (SPSS Inc., Chicago, IL, USA) for Windows ${ }^{\circledR}$. A $P$-value of $<0.05$ was regarded as significant.

\section{Results \\ Preparation and characterization of O-CNT-PEG}

TGA measurements and FT-IR spectroscopy were employed to determine wrapping the CNTs with PEG chains. In the FT-IR spectrum of O-CNT, the peaks observed at 3,409.36, 2,870, and $1,750 \mathrm{~cm}^{-1}$ were correlated to $\mathrm{O}-\mathrm{H}$ (carboxylic acid), $\mathrm{C}-\mathrm{H}$, and $\mathrm{C}=\mathrm{O}$ bonds, respectively (Figure 1). In the O-CNT-PEG, PEG-related peaks covered the peaks of $\mathrm{O}-\mathrm{CNT}$. Increase in the intensity and width of O-H peak $\left(3,409.69 \mathrm{~cm}^{-1}\right)$, C-H peak $\left(2,872.13 \mathrm{~cm}^{-1}\right)$, and C-O peak $\left(1,108 \mathrm{~cm}^{-1}\right)$ were due to the presence of PEG. Indeed, the peaks at 1,250, 1,298 and $1,351 \mathrm{~cm}^{-1}$ were due to $\mathrm{C}-\mathrm{H}$ scissoring and bending in PEG (Figure 1).

TGA measurements provided further evidence regarding the content of polymer on the surfaces of CNTs. Figure 2 shows the TGA thermograms of O-CNT and O-CNT-PEG. Wrapped PEG started to thermally degrade at $330^{\circ} \mathrm{C}$, and at $450^{\circ} \mathrm{C}$ decomposed completely. The plateau in the thermogram of O-CNT-PEG trace after $450^{\circ} \mathrm{C}$ was attributed to the carbon nanotube. According to the weight loss region, the amount of O-CNT component in the O-CNT-PEG was approximately $20 \%(\mathrm{w} / \mathrm{w})$.

Morphological changes of functionalized CNTs were assessed by FESEM (Figure 3). It was observed that a 


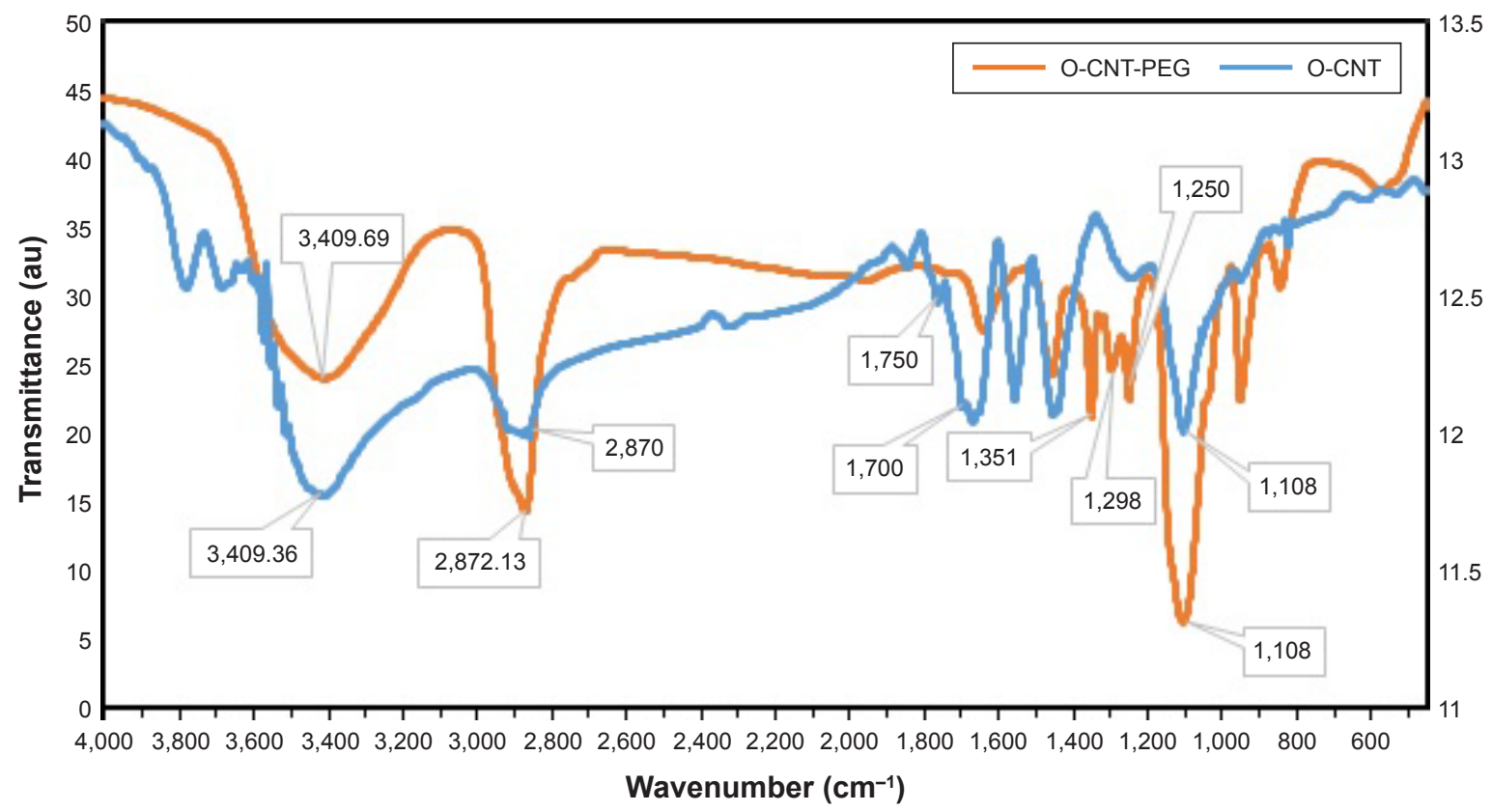

Figure I FT-IR spectrum of O-CNT and O-CNT-PEG.

Abbreviations: au, absorbance units; FT-IR, Fourier Transform infrared; O-CNT, oxidized carbon nanotube; PEG, polyethylene glycol.

continuous layer of PEG had been formed on the surface of O-CNTs.

These results indicated that PEG chains were successfully wrapped onto the CNT surfaces. Therefore, the solution of O-CNT-PEG was stable in water without aggregation over long periods of storage (several months).

UV-Vis absorption spectrum of O-CNT-PEG is shown in Figure 4. According to this spectrum curve, the maximum absorption wavelength of O-CNT-PEG was in the range of 670-940 nm. Penetration of light in skin and cells in the NIR spectrum is more convenient than visible spectrum. ${ }^{36-38}$ Therefore, the wavelength of $808 \mathrm{~nm}$ was chosen for photoexcitation.

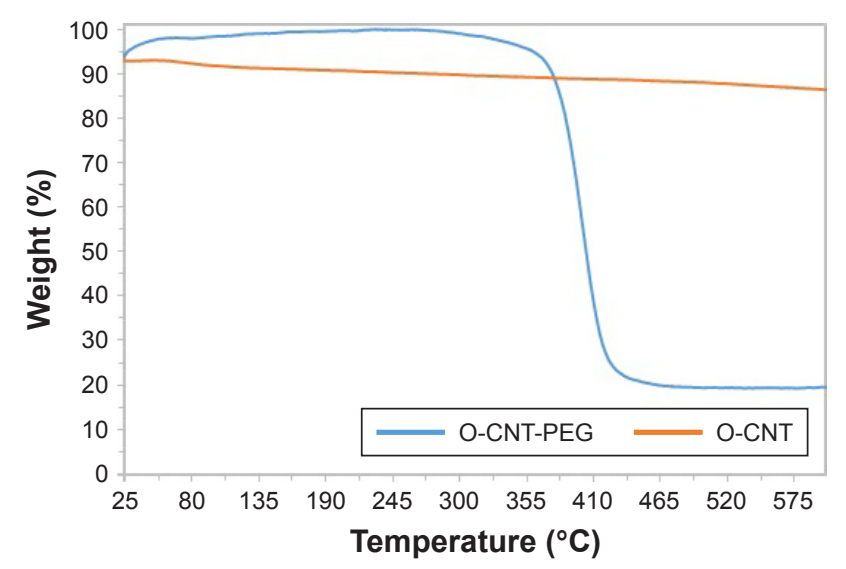

Figure 2 TGA thermo grams of O-CNT and O-CNT-PEG.

Abbreviations: au, absorbance units; O-CNT, oxidized carbon nanotube; PEG, polyethylene glycol; TGA, thermogravimetric analysis.

\section{Cell cytotoxicity of O-CNT-PEG}

The cytotoxicity profile of MWNT, O-CNT, and O-CNTPEG against the cell lines was assessed to confirm the modification of CNTs with PEG. For this purpose, the cytotoxicity of MWNT, O-CNT, and O-CNT-PEG was evaluated using the MTT assay. HeLa and HepG2 cells were exposed to that NPs at different concentrations for 24 hours and MTT assay was carried out. As shown in Figure $5 \mathrm{~A}$ and $\mathrm{B}$, at concentrations of up to $1,000 \mathrm{ng} / \mathrm{mL}$, the O-CNT-PEG NPs showed relatively low toxicity in both cell lines. Presence of PEG around the CNTs increased the cell viability significantly. Oxidation and then coating of MWNTs with PEG increased the cell viability in HepG2 and HeLa cell lines.

\section{PTT of tumors}

The in vivo effects of O-CNT-PEG with laser irradiation on the subcutaneously implanted murine melanoma were evaluated by monitoring the tumor size.

Tumor sizes were recorded before and 3 days after the irradiation. Data were analyzed, and significant difference was seen between groups I and II. The shrinking of tumor size in O-CNT-PEG group is clearly evident in Figure 6. As can be seen from this figure, the tumor size before and after the treatment in each mouse was recorded. In the control group, it is clear that the tumor growth was faster where the initial size was greater, but in the O-CNT-PEG group the tumor size was decreased in all cases. By using O-CNT-PEG 

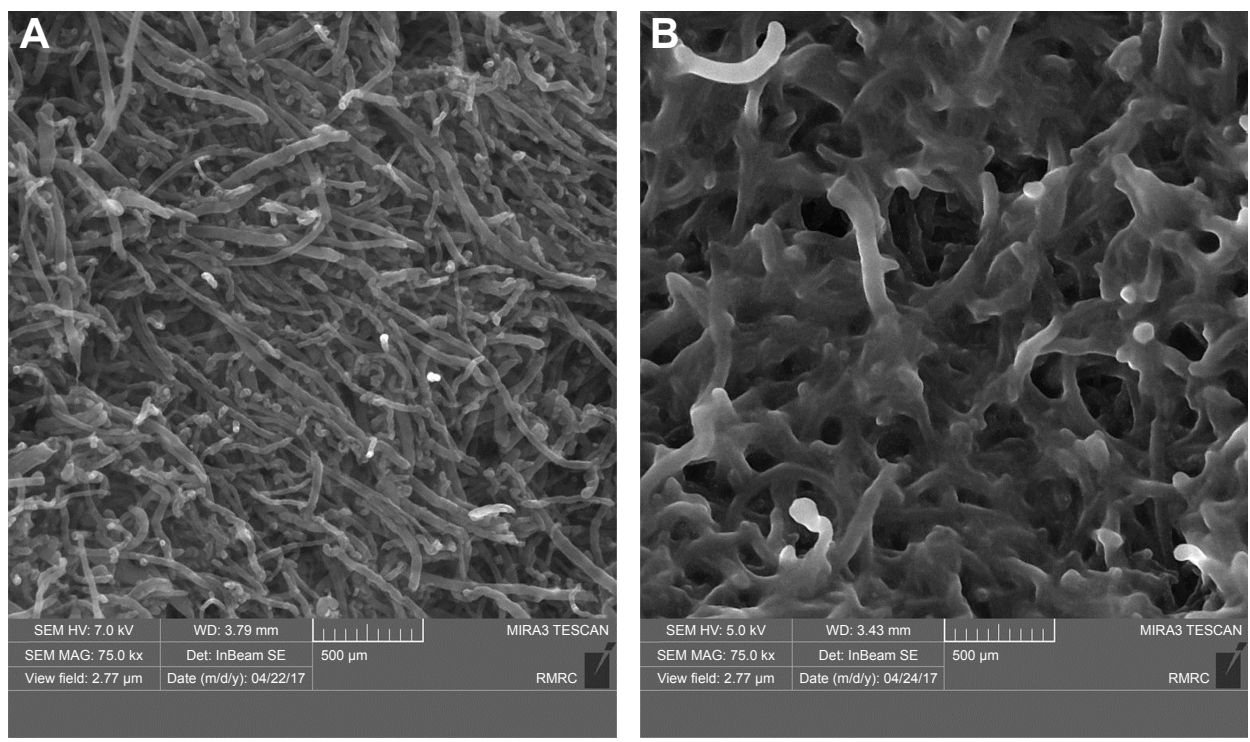

Figure 3 FESEM images of functionalized CNTs.

Notes: (A) O-CNT and (B) O-CNT-PEG.

Abbreviations: FESEM, field emission scanning electron microscopy; O-CNT, oxidized carbon nanotube; PEG, polyethylene glycol; CNT, carbon nanotubes.

NPs in laser therapy, the large tumor $\left(975 \mathrm{~mm}^{3}\right)$ shrank to a small size $\left(125 \mathrm{~mm}^{3}\right)$, while in the control group the mouse with a tumor of $1,080 \mathrm{~mm}^{3}$ died before day 3 of the study. In the laser therapy group, the tumors grew at a slower rate, and in two cases the size of the tumors decreased. This indicates that the average size of tumor before and 3 days after the treatment was increased in the control group (from $406 \mathrm{~mm}^{3}$ to $745.31 \mathrm{~mm}^{3}$, respectively), but these values decreased in the O-CNT-PEG group (from $566.4 \mathrm{~mm}^{3}$ to $174.69 \mathrm{~mm}^{3}$, respectively). The $P$-value between all groups was significantly different after treatment.

The slope of tumor size against time in the control, laser therapy, and O-CNT-PEG groups was about +113.10 $\mathrm{mm}^{3} / \mathrm{d},+14.47 \mathrm{~mm}^{3} / \mathrm{d}$, and $-130.57 \mathrm{~mm}^{3} / \mathrm{d}$, respectively (+ indicates increasing and - indicates decreasing of tumor size). The slope of tumor size reduction in O-CNT-PEG group

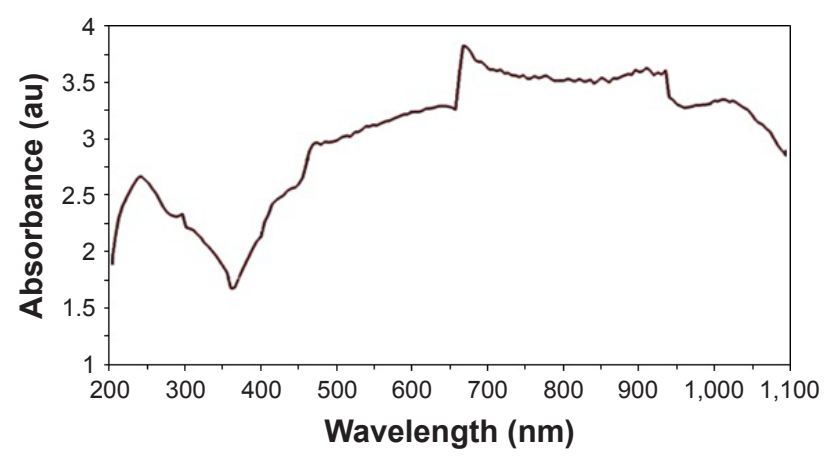

Figure 4 UV-Vis absorption spectrum of O-CNT-PEG.

Abbreviations: au, absorbance units; O-CNT, oxidized carbon nanotube; PEG, polyethylene glycol; UV-Vis, ultraviolet-visible. is remarkable. Additionally, ultrasound images were taken to define the depth of tumors in different groups. The stages of tumor treatment in O-CNT-PEG group is clear in Figure 7.

Histopathologic evaluation was performed for professional scrutiny. Gross evaluation of tumors indicated severe shrinkage of tumor size in O-CNT-PEG group in comparison with control and laser therapy groups. Microscopic evaluation showed the presence of nodular subtype malignant melanoma in all cases. Necrosis was found to be the most important discriminator between the cases, and its percentage was higher in cases allocated in O-CNT-PEG group compared to control and laser therapy groups. In the O-CNT-PEG group, a direct association was seen with the site of necrosis and deposition of NPs, which is shown in Figure 8. Mitosis was higher in the control cases while compared with the other cases. There is no evidence of regressive fibrosis, lymphocytic infiltration, vascular invasion, neurotropism, ulceration, and microsatellites in cases. The results are detailed in Table 1.

\section{Discussion}

CNTs can absorb NIR light and convert its energy into heat effectively. ${ }^{39}$ In this study, we used these NPs to evaluate their ability for tumor size reduction by PTT technique. At first, for improving the dispersibility of MWNTs in water, the hydrophilic polymer PEG was used to wrap the surface of the nanotubes. Modified MWNTs were characterized, and the formation of a thin layer of PEG around the nanotubes was established. Results of TGA showed that the amount of PEG component in the O-CNT-PEG was approximately $80 \%$ 

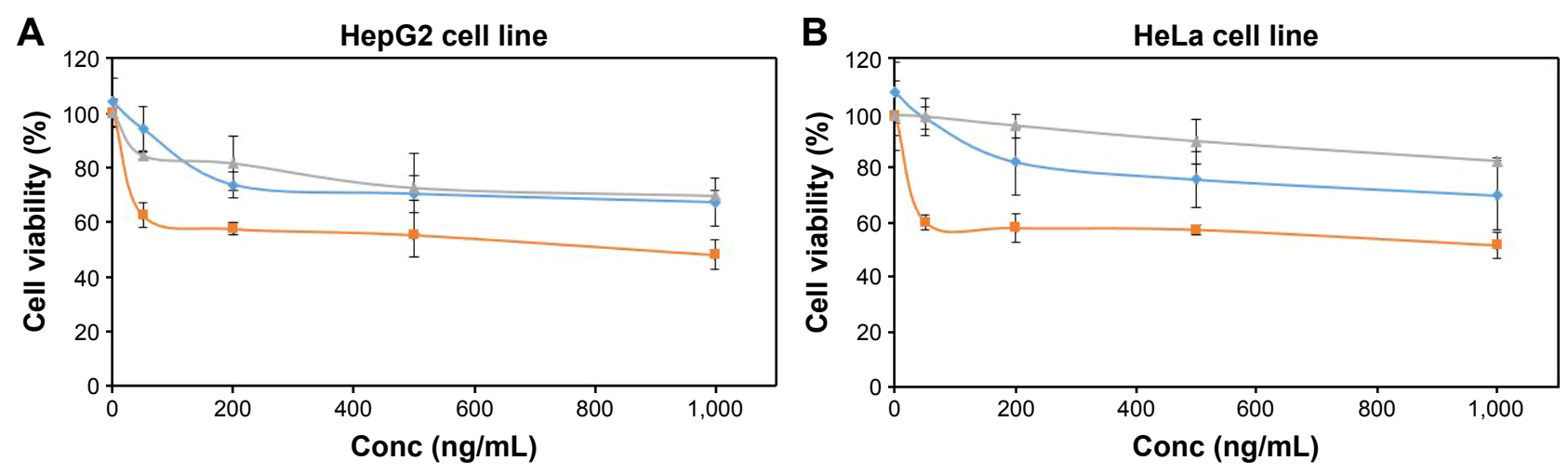

$\because$ O-CNT $\rightarrow-$ MWNT $\leadsto$ O-CNT-PEG

Figure 5 MTT assay of MWNT. O-CNT, and O-CNT-PEG against HepG2 (A) and HeLa (B) cell lines.

Abbreviations: Conc, concentration; MWNT, multiwalled carbon nanotube; O-CNT, oxidized carbon nanotube; PEG, polyethylene glycol.

(w/w). Cell cytotoxicity study showed that O-CNT was less cytotoxic than pristine MWNTs, and O-CNT-PEG had the lowest toxicity against HeLa and HepG2 cell lines. The cell viability after exposure to different NPs in HeLa cell line at all concentrations was significantly different $(P<0.05)$. But in the HepG2 cell line, the cytotoxicity of O-CNT-PEG and O-CNT in some concentrations $(500 \mathrm{ng} / \mathrm{mL}$ and $1,000 \mathrm{ng} / \mathrm{mL})$ was not significantly different $(P>0.05)$. The sensitivity of different cell lines to the same materials is different, and the concentration and duration of exposure time to the materials are also important factors for toxicity evaluation.

Melanoma was induced in mice by injection of B16/F10 cell line. For evaluation the effect of ablation with O-CNTPEG and laser irradiation, the tumor area was irradiated by an $808 \mathrm{~nm}$ CW NIR laser diode after the injection of O-CNTPEG into the tumor. The average size of tumor in mice receiving O-CNT-PEG decreased sharply in comparison with the laser therapy alone.

Pristine, as-produced CNTs have hydrophobic surface and tend to bundle up. So, these NPs are insoluble in most solvents and biological medium. ${ }^{40}$ Besides, presence of residual metal catalysts and also the insolubility of pristine CNTs cause they show more toxic effects than functionalized form of them. ${ }^{41}$ Surfactants, nucleic acids, peptides, and polymers are used for functionalization of CNTs. ${ }^{42}$ Functionalization of CNTs was done through two main approaches: noncovalent and covalent functionalization. In noncovalent functionalization, the electronic structure of the nanotubes was preserved. Indeed, functionalization through this method is often simple and reproducible. So, many researchers have recommended this approach for modification the surface of CNTs. ${ }^{40}$ Our strategy in this

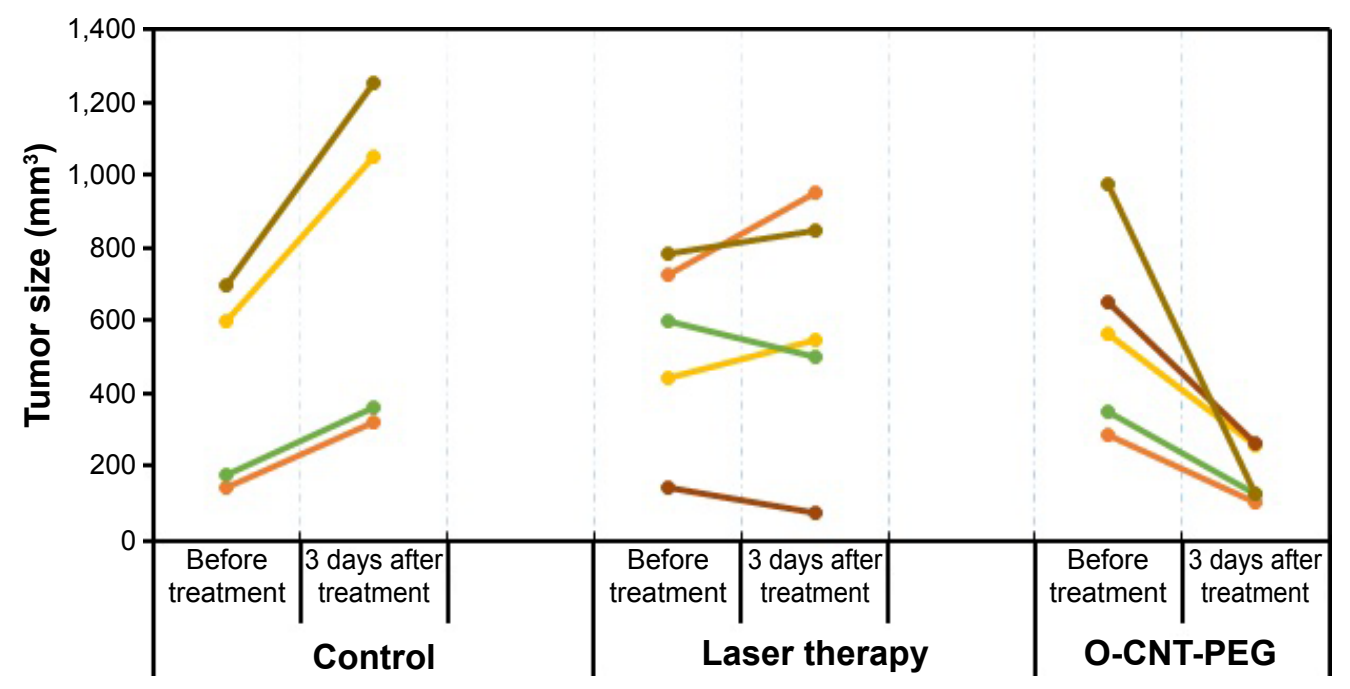

Figure 6 The size of tumors before and 3 days after the treatment with PTT in different groups. Abbreviations: O-CNT, oxidized carbon nanotube; PEG, polyethylene glycol; PTT, photothermal therapy. 


\section{A}

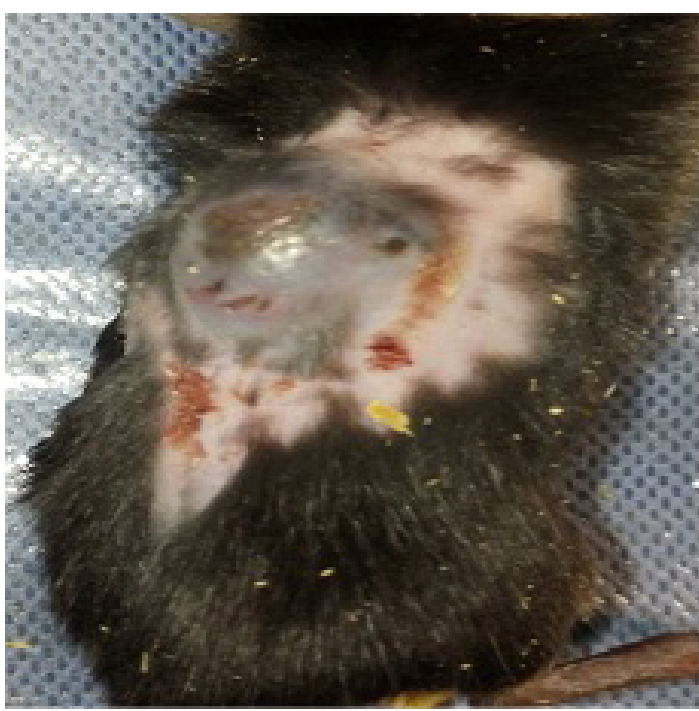

B

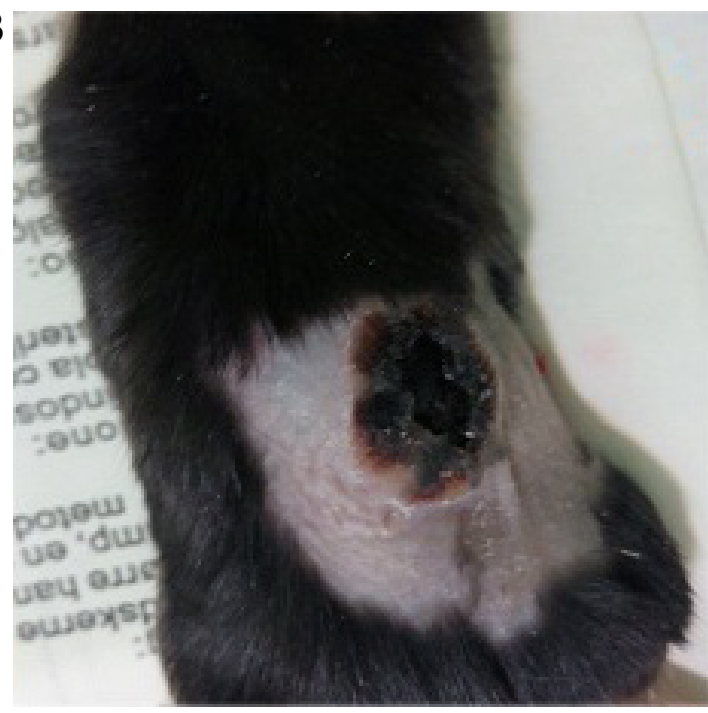

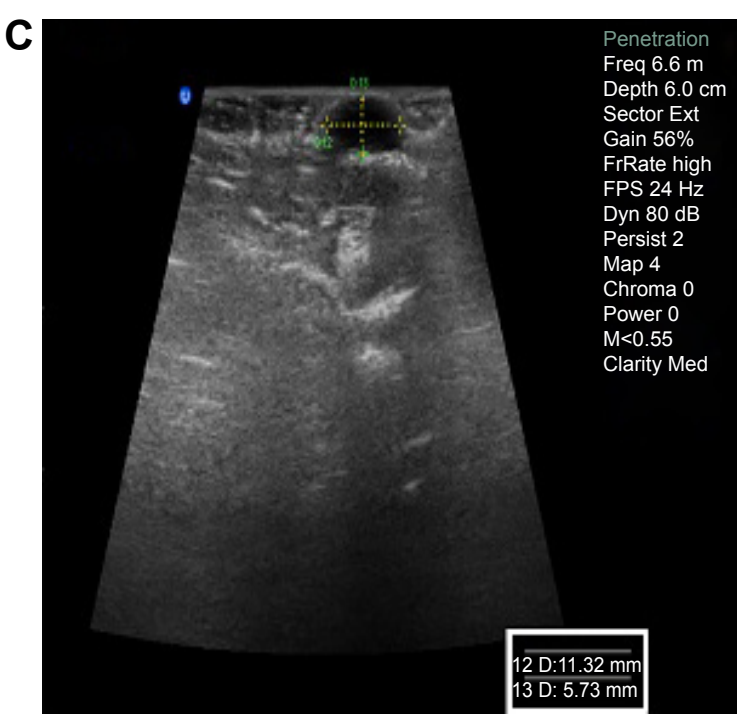

Figure 7 The stages of tumor treatment in the O-CNT-PEG group with PTT technique.

Notes: (A, C) Photograph and ultrasonography image of a cancerous mouse before the treatment, respectively. (B) Photograph of the mouse 3 days after the treatment (sonography was not feasible 3 days after the treatment).

Abbreviations: O-CNT, oxidized carbon nanotube; PEG, polyethylene glycol; PTT, photothermal therapy.

study involved the generation of dispersed MWNTs by using PEG wrapping. After oxidation of MWNTs, carboxylic acid and hydroxyl groups formed at the side and at the end of nanotubes. ${ }^{30}$ These functional groups can interact with PEG through hydrogenic bonds, and so a thin layer of polymer was formed around the surface of MWNTs. PEG is a hydrophilic polymer which can improve water dispersibility of MWNTs. In addition, coating NPs with this biocompatible and biodegradable polymer could enhance the localization of NPs in tumor region by the enhanced permeation and retention effect. ${ }^{28,29}$ The results of cytotoxicity evaluation of MWNTs showed that oxidation and then functionalization of MWNTs with PEG reduced the cytotoxicity of the NTs against two cell lines (Figure 5).
Oxidation removes residual metal catalysts, and wrapping PEG around the side of nanotubes improves the water dispersibility.

CNTs can be used as plasmonic NPs that can absorb NIR light and convert its energy to heat. ${ }^{43}$ This heat can destroy the tumor cells, which are more sensitive to elevated temperature (hyperthermia) than normal cells. Hyperthermia also increases the vascular permeability of tumor compared with normal vasculature, which can facilitate the delivery of anticancer drugs into tumors. ${ }^{39}$ Therefore, localization of plasmonic NPs in the tumor region can be an efficient strategy for treatment of solid tumors. In this in vivo ablation experiment, O-CNT-PEG was injected into the melanoma tumor, and then the solid tumor region was irradiated. The rate of 


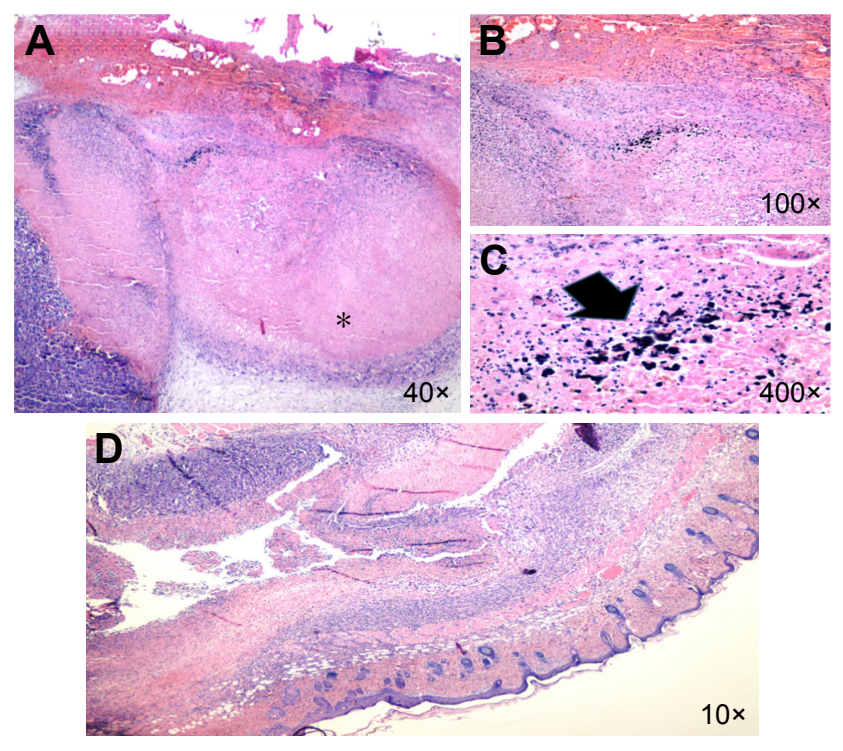

Figure 8 Malignant melanoma.

Notes: (A) (*) Histopathologic section of the laser therapy case which shows the zone of tumor necrosis (H\&E). (B, C) There is the deposition of NPs (arrow) in O-CNT-PEG group within the necrotic areas (H\&E). (D) Histopathologic section of the tumor in the case allocated to the O-CNT-PEG group which shows high percent of tumor necrosis (IOX; (H\&E)).

Abbreviations: H\&E, hematoxylin and eosin; NPs, nanoparticles; O-CNT, oxidized carbon nanotube; PEG, polyethylene glycol.

decrease of tumor size was very rapid in comparison with the group that underwent only laser therapy without any pretreatment (Figure 6). Histological observation, shown in Figure 8, demonstrated tumor necrosis.

According to these excellent results, the next step is to evaluate the efficacy of O-CNT-PEG in tumor suppression by hyperthermia therapy after intravenous injection and localization of them to the tumor through passive targeting technique.

\section{Conclusion}

In the present study, a novel O-CNT-PEG NP was evaluated to identify its healing effect in PTT technique. Irradiation of O-CNT-PEG induced heat generation and considerable damage to melanoma in vivo. Monitoring the mice after these treatment and combination therapy with anticancer agents

Table I Results of histopathologic evaluation

\begin{tabular}{llll}
\hline Groups & Necrosis (\%) & $\begin{array}{l}\text { Breslow's } \\
\text { thickness }\end{array}$ & $\begin{array}{l}\text { Tumor stage after } \\
\text { treatment according } \\
\text { AJCC 20 I0 }\end{array}$ \\
\hline O-CNT-PEG & More than $90 \%$ & About $3 \mathrm{~mm}$ & IIA \\
Laser therapy & About $25 \%$ & $>4 \mathrm{~mm}$ & IIB \\
Control & Less than $5 \%$ & $>4 \mathrm{~mm}$ & IIB \\
\hline
\end{tabular}

Abbreviations: O-CNT, oxidized carbon nanotube; PEG, polyethylene glycol. for decreasing the intensity of NIR wavelength is suggested for subsequent studies.

\section{Acknowledgment}

We specially thank the personnel of Animal Laboratory of Shiraz University of Medical Sciences, Shiraz, Iran.

\section{Disclosure}

The authors report no conflicts of interest in this work.

\section{References}

1. Peer D, Karp JM, Hong S, Farokhzad OC, Margalit R, Langer R. Nanocarriers as an emerging platform for cancer therapy. Nat Nanotechnol. 2007;2(12):751-760.

2. Singh R, Torti SV. Carbon nanotubes in hyperthermia therapy. Adv Drug Deliv Rev. 2013;65(15):2045-2060.

3. Banu H, Sethi DK, Edgar A, et al. Doxorubicin loaded polymeric gold nanoparticles targeted to human folate receptor upon laser photothermal therapy potentiates chemotherapy in breast cancer cell lines. J Photochem Photobiol B. 2015;149:116-128.

4. Sadhukha T, Wiedmann TS, Panyam J. Inhalable magnetic nanoparticles for targeted hyperthermia in lung cancer therapy. Biomat. 2013; 34(21):5163-5171.

5. Okhai TA, Smith CJ. Principles and Application of RF System for Hyperthermia Therapy. In: Huilgol N, editor. Hyperthermia. InTech; 2013:171-184.

6. Zhou F, Xing D, Ou Z, Wu B, Resasco DE, Chen WR. Cancer photothermal therapy in the near-infrared region by using single-walled carbon nanotubes. J Biomed Opt. 2014;14(2):21009.

7. Liu J, Wang C, Wang X, et al. Mesoporous silica coated single-walled carbon nanotubes as a multifunctional light-responsive platform for cancer combination therapy. Adv Funct Mat. 2015;25(3):384-392.

8. Burke A, Ding X, Singh R, et al. Long-term survival following a single treatment of kidney tumors with multiwalled carbon nanotubes and near-infrared radiation. Proc Natl Acad Sci U S A. 2009;106(31): 12897-12902.

9. Yang K, Zhang S, Zhang G, Sun X, Lee ST, Liu Z. Graphene in mice: ultrahigh in vivo tumor uptake and efficient photothermal therapy. Nano Lett. 2010;10(9):3318-3323.

10. Robinson JT, Tabakman SM, Liang Y, et al. Ultrasmall reduced graphene oxide with high near-infrared absorbance for photothermal therapy. J Am Chem Soc. 2011;133(17):6825-6831.

11. Jordan A. Hyperthermia classic commentary: "Inductive heating of ferrimagnetic particles and magnetic fluids: Physical evaluation of their potential for hyperthermia" by Andreas Jordan et al, International Journal of Hyperthermia, 1993;9:51-68. Int J Hyperthermia. 2009; 25(7):512-516.

12. Patino T, Mahajan U, Palankar R, et al. Multifunctional gold nanorods for selective plasmonic photothermal therapy in pancreatic cancer cells using ultra-short pulse near-infrared laser irradiation. Nanoscale. 2015;7(12):5328-5337.

13. Day ES, Thompson PA, Zhang L, et al. Nanoshell-mediated photothermal therapy improves survival in a murine glioma model. J Neuro-Oncol. 2011;104(1):55-63.

14. Ma Y, Liang X, Tong S, Bao G, Ren Q, Dai Z. Gold nanoshell nanomicelles for potential magnetic resonance imaging, light-triggered drug release, and photothermal therapy. Adv Funct Mat. 2013;23(7): $815-822$.

15. Roti Roti JL. Cellular responses to hyperthermia (40-46 degrees C): cell killing and molecular events. Int J Hyperthermia. 2008;24(1):3-15.

16. Shcherbakova DM, Verkhusha VV. Near-infrared fluorescent proteins for multicolor in vivo imaging. Nat Methods. 2013;10(8):751-754. 
17. Filonov GS, Piatkevich KD, Ting LM, Zhang J, Kim K, Verkhusha VV. Bright and stable near-infrared fluorescent protein for in vivo imaging. Nat Biotechnol. 2011;29(8):757-761.

18. Markovic ZM, Harhaji-Trajkovic LM, Todorovic-Markovic BM, et al. In vitro comparison of the photothermal anticancer activity of graphene nanoparticles and carbon nanotubes. Biomaterials. 2011;32(4): 1121-1129.

19. Sailor MJ, Park JH. Hybrid nanoparticles for detection and treatment of cancer. Adv Mat. 2012;24(28):3779-3802.

20. Iancu C, Mocan L. Advances in cancer therapy through the use of carbon nanotube-mediated targeted hyperthermia. Int J Nanomed. 2011;6:1675-1684.

21. Huang X, El-Sayed MA. Plasmonic photo-thermal therapy (PPTT). Alexandria J Med. 2011;47(1):1-9.

22. Kroemer G, Galluzzi L, Kepp O, Zitvogel L. Immunogenic cell death in cancer therapy. Ann Rev Immunol. 2013;31(1):51-72.

23. Robinson JT, Welsher K, Tabakman SM, et al. High performance in vivo near-IR $(>1 \mu \mathrm{m})$ imaging and photothermal cancer therapy with carbon nanotubes. Nano Res. 2010;3(11):779-793.

24. Murphy FA, Poland CA, Duffin R, et al. Length-dependent retention of carbon nanotubes in the pleural space of mice initiates sustained inflammation and progressive fibrosis on the parietal pleura. Am J Pathol. 2011;178(6):2587-2600.

25. Xu H, Cheng X, Zhong J, et al. Characterization of multiwalled carbon nanotubes dispersing in water and association with biological effects. J Nanomat. 2011;2011.

26. Ling X, Wei Y, Zou L, Xu S. The effect of different order of purification treatments on the purity of multiwalled carbon nanotubes. App Surf Sci. 2013;276:159-166.

27. Liu Z, Tabakman S, Welsher K, Dai H. Carbon nanotubes in biology and medicine: In vitro and in vivo detection, imaging and drug delivery. Nano Res. 2009;2:85-120.

28. Gong H, Peng R, Liu Z. Carbon nanotubes for biomedical imaging: the recent advances. Adv Drug Deliv Rev. 2013;65(15):1951-1963.

29. Shen C, Brozena AH, Wang Y. Double-walled carbon nanotubes: challenges and opportunities. Nanoscale. 2011;3(2):503-518.

30. Sobhani Z, Dinarvand R, Atyabi F, Ghahremani M, Adeli M. Increased paclitaxel cytotoxicity against cancer cell lines using a novel functionalized carbon nanotube. Int J Nanomed. 2011;6:705-719.
31. Pifferi V, Cappelletti G, Bari C Di, Meroni D, Spadavecchia F, Falciola L. Multi-Walled Carbon Nanotubes (MWCNTs) modified electrodes: effect of purification and functionalization on the electroanalytical performances. Electrochim Acta. 2014;146:403-410.

32. Tsai PA, Kuo HY, Chiu WM, Wu JH. Purification and functionalization of single-walled carbon nanotubes through different treatment procedures. J Nanomat. 2013;2013:1-9.

33. Jahanbakhsh R, Atyabi F, Shanehsazzadeh S, Sobhani Z, Adeli M, Dinarvand R. Modified gadonanotubes as a promising novel MRI contrasting agent. DARU J Pharm Sciences. 2013;21(1):53.

34. Jensen MM, Jørgensen JT, Binderup T, Kjaer A. Tumor volume in subcutaneous mouse xenografts measured by microCT is more accurate and reproducible than determined by $18 \mathrm{~F}-\mathrm{FDG}$-microPET or external caliper. BMC Med Imag. 2008;8(1):16.

35. Yan D, Teng Z, Sun S, et al. Foot-and-mouth disease virus-like particles as integrin-based drug delivery system achieve targeting anti-tumor efficacy. Nanomedicine. 2017;13(3):1061-1070.

36. Shan G, Weissleder R, Hilderbrand SA. Upconverting organic dye doped core-shell nano-composites for dual-modality NIR imaging and photo-thermal therapy. Theranostics. 2013;3(4):267-274.

37. Luo S, Zhang E, Su Y, Cheng T, Shi C. A review of NIR dyes in cancer targeting and imaging. Biomaterials. 2011;32(29):7127-7138.

38. Sowa P, Rutkowska-Talipska J, Rutkowski K, Kosztyła-Hojna B, Rutkowski R. Optical radiation in modern medicine. Adv Dermatol Allergol. 2013;4(4):246-251.

39. Hashida Y, Tanaka H, Zhou S, et al. Photothermal ablation of tumor cells using a single-walled carbon nanotube-peptide composite. J Control Release. 2014;173(1):58-66.

40. Klumpp C, Kostarelos K, Prato M, Bianco A. Functionalized carbon nanotubes as emerging nanovectors for the delivery of therapeutics. Biochim Biophys Acta. 2006;1758(3):404-412.

41. Firme CP 3rd, Bandaru PR. Toxicity issues in the application of carbon nanotubes to biological systems. Nanomedicine. 2010;6(2):245-256.

42. Foldvari M, Bagonluri M. Carbon nanotubes as functional excipients for nanomedicines: I. pharmaceutical properties. Nanomedicine. 2008; 4(3):173-182.

43. Chakravarty P, Marches R, Zimmerman NS, et al. Thermal ablation of tumor cells with antibody-functionalized single-walled carbon nanotubes. Proc Natl Acad Sci. 2008;105(25):8697-8702.
International Journal of Nanomedicine

\section{Publish your work in this journal}

The International Journal of Nanomedicine is an international, peerreviewed journal focusing on the application of nanotechnology in diagnostics, therapeutics, and drug delivery systems throughout the biomedical field. This journal is indexed on PubMed Central, MedLine, CAS, SciSearch $®$, Current Contents $\AA /$ Clinical Medicine,

\section{Dovepress}

Journal Citation Reports/Science Edition, EMBase, Scopus and the Elsevier Bibliographic databases. The manuscript management system is completely online and includes a very quick and fair peer-review system, which is all easy to use. Visit http://www.dovepress.com/ testimonials.php to read real quotes from published authors. 